\title{
Essential English for Pilotage and Tug Assistance - Proposal for SMCP Extension
}

\author{
Adelija Čulić-Viskota
}

This paper aims at presenting the activities undertaken since 2012 by the G.A.M.E. - Gesellschaft für Ausbildung in Maritimem Englisch (German Association for Maritime English) with the seat at Bremen University of Applied Sciences, Nautical Department and presided by Capt. Willi Wittig, Head of the Department. The Association gathers Maritime English instructors and maritime professionals who have recently focused on updating the existing Standard Marine Communication Phrases - SMCP - in order to better match the ever growing requirements in maritime affairs. The emphasis has been put on the pilotage and tug assistance phrases, as the existing body of phrases has not been felt entirely suitable to the activities performed. Thus, Capt. Matthias Meyer, master mariner and lecturer at the Nautical Department of the University of Applied Sciences in Bremen, former elder brother of Port Pilot Society Bremerhaven, was entrusted with the task of proposing a further development of the phrases related to this particular seafaring activity. The other lecturers, including the author of the paper, contributed during the 2014 G.A.M.E. summer seminar to Capt. Meyer's proposal purely from the linguistic or methodical point of view.

\section{KEY WORDS}

$\sim$ SMCP

$\sim$ Maritime English

$\sim$ Extension

$\sim$ Pilotage

$\sim$ Tug assistance

University of Split, Faculty of Maritime Studies, Split, Croatia e-mail: adelija@pfst.hr
"Here's to the Pilot that weather'd the storm."

George Canning

\section{INTRODUCTION}

Since English has conquered seas worldwide and become the master key to communication on board every vessel, the need has been felt to provide a common, but limited set of phrases to allow seafarers to communicate in a simple, understandable, unambiguous and effective manner. This tendency gave rise first to SMNV (Standard Marine Navigational Vocabulary) in 1977, subsequently to Blakey's Maritime English in 1983 and Week's Wavelength in 1986, SEASPEAK project, also led by Weeks, and then SMCP (Standard Marine Communication Phrases) as they are globally used today. As described on the IMO's website, "?IMO's Standard Marine Communication Phrases (SMCP) were adopted by the 22nd Assembly in November 2001 as resolution A.918(22) IMO Standard Marine Communication Phrases. ... The IMO SMCP replaced the Standard Marine Navigational Vocabulary (SMNV) adopted by IMO in 1978 (and amended in 1985).

The SMNV was developed for use by seafarers, following agreement that a common language - namely English - should be established for navigational purposes where language difficulties arise and the IMO SMCP have been developed as a more comprehensive standardized safety language, taking into account changing conditions in modern seafaring and covering all major safety-related verbal communication.

The IMO SMCP include phrases which have been developed to cover the most important safety-related fields of verbal shore-to-ship (and vice-versa), ship-to-ship and on- 
board communications. The aim is to get round the problem of language barriers at sea and avoid misunderstandings which can cause accidents.

The IMO SMCP build on a basic knowledge of English and have been drafted in a simplified version of Maritime English. It includes phrases for use in routine situations such as berthing as well as standard phrases and responses for use in emergency situations.

Under the International Convention on Standards of Training, Certification and Watchkeeping for Seafarers (STCW), 1978 , as amended, the ability to understand and use the SMCP is required for the certification of officers in charge of a navigational watch on ships of 500 gross tonnage or above."

There are several points to be emphasized here:

1. The use of the mother tongues of crew members on board has never been encouraged in order for better understanding to be achieved among multicultural and multilingual crews, and the use of a common language is the most straightforward way of reaching this target. So, Trenkner (2013: 28) believes that the approach to the problem should be different from what is laid down in SOLAS 2004. In Nautilus Telegraph, dated February 2013, he says: "SOLAS 2004 specifies that English must be used between ship and shore, and between a ship's crew and a pilot, but it does not actually require English to be used among fellow crew members". Maritime professionals worldwide are definitely in favour of his proposal to make use of English for all forms of communication conducted on board vessels, just as it is the case in aviation. Moreover, Cole and Trenkner (2012:5) support the overall use of the English language on board modern vessels by noting: "It is worth noting, however, that on board Imperial German men -of-war of the period, at a time when relationships with the British Royal Navy were far from congenial, amazingly English was the command language up until 1905, and was frequently the medium of understanding among German navy men on shipboard, too. The crews for on board service were not drafted from conscripts but recruited from volunteers of the German merchant marine where English had already widely been accepted as sort of working language. From the last quarter of the 19 th century until the 1920s and 30s so-called mixed crews were anything else but isolated cases, and ship owners or senior officers simply expected their ratings and junior officers to have sufficient English language skills to enable them to properly do their work on board -in fact, an insufficient command of English was regarded as "bad seamanship"."

The use of SMCP is advisable as the best course of action in circumstances "where language difficulties arise". The circumstances in which the bridge team is extended to the pilot, who often has to involve persons external to the ship's crew into communication during pilotage and situations requiring tug assistance, definitely call for use of an enhanced form of SMCP intended for this complex scene, the first and foremost objective being to avoid language difficulties leading to accidents.

2. The next important point is that SMCP have been established as "standardized safety language", which points out its particular purpose and importance for the safe operation of ships. They have been developed on the basis of SMNV to become its "more comprehensive" version aimed at covering an increasing number of ship's operations. Since it is important for a communication code to keep pace with the "changing conditions in modern seafaring", further initiatives of SMCP extension or enlargement of the body of phrases can be expected in the future.

3. It is of utmost importance to use a common communication tool such as SMCP to prevent misunderstandings which can lead to accidents. Thus, with such a large number of accidents occurring due to deficient, ineffective communication, it is definitely safer to resort to the common code in order to provide for the safety of all the parties involved.

4. Not only emergency situations are covered by SMCP, although in such cases the use of Phrases can be of vital importance. But they are also intended for "routine situations". It has been on the basis of this use of SMCP that the need has been felt to enlarge the body of phrases available so far for the pilotage and tug assistance situations. In his elaboration of the problem entitled "English as Working Language during Manoeuvring" at the $201238^{\text {th }}$ IFSMA General Assembly held in Copenhagen, Capt. Meyer stated that ${ }_{1 . . .}$ there is no doubt, more than $95 \%$ of the daily work of a harbour pilot is standard." So, although some $5 \%$ of the situations refer to uncommon circumstances during berthing, unberthing, Capt. Meyer is in favour of extending the SMCP to those standard procedures. Consequently, after a discussion IFSMA res. 1/2012 (AGA 38), Further Development of SMCP (Standard Marine Communication Phrases) was accepted in Copenhagen.

5. The ability to understand and use the SMCP is required for the certification of officers in charge of a navigational watch on ships of 500 gross tonnage or above, which refers to all the participants in the Master-Pilot-Tug communication. Therefore, Capt. Meyer ends his contribution in the IFSMA Annual Review 2011-2012 (2012:12-13) by his deep conviction: "All involved masters commanding the vessel, commanding the tug or serving as pilot are holding the same licence. Due to this standard the communication skills should be on B1 level in accordance with CEFR (Common European Framework of Reference for Languages). To improve the safety of the vessel and the traffic on the waterways, to provide a better legal protection for the master and, last but not least, to protect the environment, a standard vocabulary has to be developed and added to the IMO Standard Marine Communication Phrases Part A V.". 


\section{FURTHER DEVELOPMENT OF SMCP}

Standard phrases and words to be used in maritime safety communications are laid down in IMO Standard Marine Communication Phrases. Among them, there is the phrase "Please, use SMCP!" meaning "Use SMCP during this conversation!", obviously with the aim of avoiding possible misunderstandings likely to arise. Likewise, whenever Maritime English tools, such as SMCP, are felt not to support appropriately the team work by allowing full grasp of the situation (situational awareness), i.e. in case they are felt as deficient in providing appropriate coverage of the activities taking place, such as the case with pilotage and tug assistance, the need is felt to elaborate on and extend the body of phrases. A participant in the on-board communication should always feel free to require from other participants to switch to SMCP in case he/she feels not able to follow. Such is the case of pilot on board arranging tugs to assist the vessel.

\subsection{The role of G.A.M.E.}

G.A.M.E. - Gesellschaft für Ausbildung in Maritimem Englisch (German Association for Maritime English) with the seat at Bremen University of Applied Sciences, Nautical Department and presided by Capt. Willi Wittig, Head of the Department, is a non-governmental, non-profit association of Maritime English lecturers and maritime professionals active worldwide either in maritime affairs, or education and training, or both. The Association is headed by Capt. Willi Wittig, with at his side the renowned prof. Hans Rummel, specialized in Maritime English during his long teaching career from 1972 to 2006 at the Universities of Applied Sciences in Bremen and Bremerhaven, retired but still active and sharing his enormous knowledge and experience with lecturers and students internationally. The Honorary Member of G.A.M.E., prof. Peter Trenkner, of Wismar University of Applied Sciences, the primary responsible for the development of the SMCP, was presented with the project idea, which was discussed and approved.

G.A.M.E. organizes workshops and seminars for Maritime English lecturers on a yearly basis, usually one-day workshop to shortly introduce and determine the topic to elaborate on the following year during the three-day seminar with the participation of all the lecturers interested in the topic and feeling capable of making a contribution. G.A.M.E. seminars are practically oriented, applied-linguistics seminars, their main purpose being Maritime English development and its implementation into maritime courses. Thus, G.A.M.E. 2014 summer seminar entitled "Proposal for Phrases on Pilotage and Tug Assistance (SMCP)" took place in Bremen from June 10-13, 2014. After a presentation by Capt. Meyer, the 2012 Annual General Assembly of the International Federation of Shipmasters'
Associations (IFSMA) passed a resolution stating the need for an extension of the SMCP on pilotage and tug assistance. During the seminar, the lecturers gathered first to revise the first draft proposal made by Capt. Meyer during the 2013 Bremen workshop and then, after a discussion with pilots from the ports of Bremerhaven and Hamburg, to round up the picture of their needs during pilotage and tug assistance in order to be able to contribute to a further development and subsequent curricular implementation of the SMCP chapter extended. A subsequent professional contribution was also made by Capt. Russo, former chief pilot in the port of Split, Croatia.

\section{THE NATURE OF MASTER-PILOT-TUG COMMUNICATION}

The ship's master, pilot and tug master represent a form of joint enterprise with the aim of safely conducting the ship to her berth or seeing her out when she is leaving it. The importance of "good chemistry" between the pilot and the ship's master is often mentioned in this context, actually referring to the communication between them. The ship's master may, of course, decide to rely completely on the pilot's competency, but he should definitely be given the chance to decide so on his/her own by being able to follow the pilot's communication with the external parties, especially with the tug master(s).

\subsection{The problems related to master-pilot-tug communication}

A realistic account of the importance of good communication among the three pivotal points of the bridge team is provided in an article by Capt. Erik Blom, Master of the M/V BLACK WATCH, Fred. Olsen Cruise Lines, entitled "Is the pilot a part of the bridge team?". The author describes the situation as follows:

"I have recently returned from a voyage to the French part of Canada. In St. Lawrence River ships the same size as mine always have two pilots on board taking one hour watches. As in many other countries, a new generation of pilots is being trained and in addition to the two pilots we had apprentices on board. It was too easy for them to fall back on speaking French between themselves instead of speaking English and in turn creating two "bridge teams", which should be avoided. Sometimes it is not possible to avoid two teams due to communication difficulties, either on the crew or on the pilot's side. Based on my experience, most pilots speak more than good enough English, but as a pilot conning a ship heading for Mongstad oil terminal I have experienced that my helm orders had to be translated into three different languages before they were executed by the helmsman. In that situation it was difficult to establish a closed loop." 
Not only does Capt. Blom insist on the importance of effective communication among the bridge team members, but he also expresses his being in favour of communication conducted in one language only, which has already traditionally become English.

In another article entitled "Pilot on board!" other obstacles to effective communications are presented, which are so complex by nature that deficient knowledge or total inability to conduct communication in English can only make things even worse. Thus, cultural differences should also be taken into consideration:

"The pilot is perceived as an authority and in many cultures it is difficult to correct or even question a decision made by an authority. Corrections to obvious errors may therefore be delayed and in some cases not put forward at all. Reluctance to get involved in a situation has contributed to several severe marine accidents. In particular, this may be a problem when the master is not on the bridge. It is therefore important that all members of the bridge team have the necessary authority and confidence to interfere if they are in doubt. This can only be achieved by active leadership and involvement by the master. The IMO Code of Nautical Procedures and Practices also states: "If in any doubt as to the pilot's actions or intentions, the officer in charge of the navigational watch shall seek clarification from the pilot and, if doubt still exists, shall notify the master immediately and take whatever action is necessary before the master arrives".

This, obviously, also applies to the tug assistance and the relative communication, which should be conducted in a language common to all the parties involved. So, if communication is conducted in a common language, i.e. Maritime English, the possibility of a breakdown is minimized.

In another article entitled "Who is to blame?", which appeared in Gard News 173, February/April 2004, the author refers to this instance of communication while describing an accident which occurred during tug assistance:

"The pilot, when communicating with the tugs, was speaking a language that was not understood by the master. This made it difficult for the master to be fully aware of the situation."

The above mentioned communication breakdown is listed as one among several important factors which contributed to the accident and which can all be found in a large number of other casualty reports.

\subsection{Early initiatives for the standardization}

It was as early as September 21, 2009 that Capt. G. V. Brooks and Capt. V. J. Schisler published an article entitled "Standardized tractor tug commands for ship-assist work" in "The Professional Mariner", Journal of the Maritime Industry. They reported of their attempt to standardize tractor commands as they conducted training of pilots in the use of tractors at marine simulators. They also suggested: "Of course, these commands, if used, need to be understood by the tug crews, and they need to have practiced the higher-speed manoeuvres before it would be appropriate to perform them with a ship." Thus, the authors put emphasis both on the need to use standardized phrases and on the need to train the crews before they use the phrases in real-life situations.

In October 2009, the American tug masters decided to express their support to the standardization of pilot - tug master command language, the issue that had previously been considered by Capt.'s Brooks and Schisler, in an article on the international towmasters' forum by saying: "As is often the case, different people will say (and mean) the same thing in varying (read: inconsistent) ways. Sometimes this inconsistency in the choice of words may even come from the same individual on the same job. When this happens misunderstandings can easily occur which may lead to groundings, damage to piers or other vessels, oil spills and personnel injuries. Capt.'s Greg Brooks and Victor Schisler are attempting to reduce some of these miscues and improve operational safety and effectiveness for tractor tugs by standardizing the terminology that ship pilots use to give them manoeuvring orders. Another key element is their recommendation to eliminate the use of words that may sound alike but have completely different meanings." ... "It should go without saying that this problem is by no means particular to tractor tugs, but I'll say it anyway. A lack of effective communication, directly or indirectly, is the root cause of many mishaps and everyone can improve their chances of safely completing any given evolution by continually working to fine tune the flow of information in both directions."

Furthermore, in April 2011 another article entitled "Side bitt or shoulder bitt? Mariners invited to standardize towing terms" and written by Brian Gauvin, the Journal's Gulf Coast correspondent appeared in "The Professional Mariner". The author reports of Capt. Eric Johansson's work on the standardization of towing nomenclature, a task undertaken by this professor at the State University of New York Maritime College following an invitation by his college back in May 2008. It was after a meeting of the representatives of the major U.S. towing companies, maritime academies and the National Maritime Safety Advisory Committee that the task of standardizing terminology to be put into consistent use was stated because, as prof. Johansson pointed out, "Ambiguity is downright dangerous in any situation and a formidable link in the error chain". (ibid.)

At the same time G.A.M.E. was invited to consider the communication problem of the bridge team during pilotage and tug assistance, and to propose an extended body of phrases that would allow pilots more precious time by relieving them from the obligation to translate their commands for the ship master into English if communication between the pilot and tug master(s) is conducted in the local language other than English.

Finally, it has to be mentioned that the need for the standardization was also felt among the Japanese and it resulted in a paper entitled "Proposal for Global Standard 
Maneuvering Orders for Tugboats", by Ishigura \& Sugita, Hayashi \& Murai, published in TransNav, the International Journal on Marine Navigation and Safety of Sea Transportation after the presentation held at the 10th International TransNav Conference in Gdynia, in June 2013. The authors focused on investigating the time lag between when a manoeuvring tug order is given and when the expected action is taken. They emphasize that "... also the purpose here is to propose the global standardization of maneuvering orders for tugboats, showing the problems caused by using special tug orders in Japan, and weighing how the orders for tugboats are employed in Japan and other foreign countries. ... Here, we recommend and propose that globally-standardized orders for manoeuvring a tug are settled and included in SMCP for the bridge team to serve its function for maritime safety". The authors expressed their awareness of the need for the standardization, which was based on their research, but did not make an actual proposal for the phrases.

\subsection{The SMCP extension to provide for "English-biased" communication during tug assistance}

The G.A.M.E. working group has taken into consideration the already existing body of the phrases intended for communication during pilotage and tug assistance. What was considered deficient were the commands issued by the pilot on the bridge to the assisting tugs, as it is of utmost importance that this instance of communication is understood by the master of the vessel being assisted.

The SMCP have been developed following certain "Basic communicative features" (IMO SMCP: 2-3) which means that "It was drafted intentionally in a simplified version of Maritime English in order to reduce grammatical, lexical and idiomatic varieties to a tolerable minimum, using standardized structures for the sake of its function aspects..."; "This means that in phrases offered for use in emergency and other situations developing under considerable pressure of time or psychological stress, as well as in navigational warnings, a block language is applied which uses sparingly or omits the function words the, a/an, is/are, as done in seafaring practice."; "Further communicative features may be summarized as follows: avoiding synonyms, avoiding contracted forms,... providing one phrase for one event...."

The G.A.M.E. working group has borne these principles in mind during the relative seminars and has done its best to remain on that course by making use as much as possible of the lexical items used in the rest of the SMCP and avoiding any varieties to make the phrases as easily memorable as possible, following the principle of consistency; also, the activities during pilotage and tug assistance bring about considerable stress to all involved, so that only the essential lexical items have been focused on, and function words, such as articles, omitted wherever possible.

\subsection{Implementation of phrases on pilotage and tug assistance into teaching}

An agreement has been reached that a consistent glossary of basic terms related to tugs and tug assistance should be developed in order for the body of phrases to be more easily introduced into a Maritime English course. Meanwhile, terminology can be taught at different stages of a Maritime English course, e.g. when teaching types of ships, tug-specific terminology can be more closely dealt with, while manoeuvring and tug assistance-related terminology can be taught while introducing berthing/unberthing. It is certainly the case that different lecturers favour different approaches, but it is always helpful to rely as much as possible on pictures and video clips when teaching terminology, since this allows the lecturer to elicit a number of wh-questions and answers. It also makes it easier to disambiguate certain lexical items, e.g. bitts and bollards, which are often confused by younger students. Also, exercises based on filling in the blanks with appropriate terms, where each term to be filled in a blank is described with relevant details. Next, exercises of guessing the term can be used. In this case, the lecturer provides pieces of information one by one until the students are able to guess the term in question, or vice versa: the lecturer introduces the term and asks the students to provide as much information on it as they can. This exercise can be prepared by the lecturer, or he/she can ask a group of students to search for information on several important terms and present it to the rest of the group in an interactive manner. Next, a useful exercise can be that of matching related terms with their descriptions, as it allows clear distinction among e.g. towing line, messenger line, hawser, monkey's fist. Although there are lots of possibilities in teaching terminology, a simple introduction of terms and assigning tasks related to the terms in question to students always works out best. It makes each student actively participate by his/her presentation of a term and eventually, they put their contributions together to make a presentation on tugs and towing equipment. The lecturer's task should be in the first place that of a consultant, e.g. in case the students find more synonymous terms for a single part of equipment, which are currently also in use or were formerly used, but are not recommended any longer. As for the newly developed phrases, they fall into three main sets according to their function. These are:

1. phrases intended for calling the tug(s),

2. phrases to express power commands,

3. phrases to express manoeuvring commands.

When calling the tug(s), different methods are used, and they have all been retained as alternative in the proposed phrases, i.e. calling the tugs by position (forward, aft) with regard to the vessel, by names (in case there is no possibility of their being misunderstood), or by numbers in combination with $\mathrm{P}$ for port and S for starboard. 
As regards the phrases to express power commands, the instruction "Power up/down to..." followed by the numerical expression of percentage of engine power or bollard pull has been proposed. Such a phrase is immediately followed by the phrase expressing new speed in knots.

Finally, the most elaborate set of phrases refers to the tug's working directions or manoeuvring. The command "Pull to ..." is followed by the direction expression using designation"... o'clock", as the assisted vessel's heading is considered to be 12 o'clock. Next, the length of and stress in the towing line have been taken into consideration, so that the following set of phrases refers to situations when the towing line has to be paid out or shortened up, kept tight or slacked away. Then, the situation when the tug accompanies the vessel with the towing line slack has been covered as well as the requirement for indirect towing. Finally, phrases intended for berthing the vessel by turning her, pushing or pulling have been added. Another important warning has also been included in the proposed phrases, i.e. the warning for the tug(s) that the vessel would start her engines ahead/astern, as well as the warning for the vessel not to start her engines. A final announcement for the tug(s) follows to state, before the "letting go" phrase, that the towing operation has finished. To finish with, there has been included a phrase allowing the pilot to announce to the tug(s) to stand by and, finally, to be released. The proposed extension has carefully been thought and adapted to the already existing SMCP phrases for tug assistance.

A suggestion for gap-filling exercise on SMCP phrases for tug operation was made by Uwe-Michael Witt, PhD., an independent expert in Maritime English delivering courses for crew members and shore-based staff, with an experience in teaching Maritime English to tug crews. The exercise includes inserting tug-operation-specific terms into the text after having heard the complete communication exchange between the pilot and the tug in order to berth the vessel safely. Next, reading the text in pairs is suggested. Finally, a still more active involvement of students is proposed by asking them to write an example of communication exchange for tug assistance during leaving berth and also to produce the exchange in speech.

Of course, the phrases developed to complement the already existing SMCP chapters on pilotage and tug assistance would also make part of the training courses for pilots and tug crews.

\subsection{Current status of the Proposal}

As required by the Annex 2 of the resolution A.918(22), "Procedure for amending the IMO Standard Marine Communication Phrases", the Proposal for the amendment to the SMCP for pilotage and tug assistance developed by G.A.M.E., after an invitation from IFSMA, is to be submitted to the IMO Maritime Safety Committee for examination and evaluation.

\section{INSTEAD OF CONCLUSION}

In this paper, the author's first and foremost objective has been to present an initiative not only to further develop Maritime English as working language, but particular emphasis has been put on the "English-bias" for pilotage and tug assistance activities. Namely, pilots on the bridge are certainly under pressure brought about by the nature of the activity itself, and what they need least is to take over another role, i.e. that of the interpreter. Communication with the members of the bridge team intertwined with communication with the tug master(s) is already a complex enough task for the pilot so as not to be overloaded with the responsibility of translating into English the tug commands for the ship's master. What is more, it is not only the question of overload, but very often it is the question of shortage of time at disposal. On the other hand, the ship's master has the overall responsibility for the ship and, as such, should definitely be in the position to object to the pilot's moves if he/ she does not agree. This, naturally, can be done only if he/she can have a full grasp of the situation. In this way, the ship's master is not put under stress by being excluded from the process through which his/her ship is conducted. At the same time, the pilot can concentrate on his job instead of taking on an additional role.

In this sense, it should be the task of Maritime English lecturers and their associations to help develop Maritime English as working language whenever an initiative comes from the maritime industry for the coverage of a specific activity or a new form of marine business to be put into use and at the disposal of all those involved in maritime affairs, for better safety of persons, property and environment.

\section{REFERENCES}

Brooks, G. V. and Schisler, V. J., (2009), Standardized tractor tug commands for ship-assist work, The Professional Mariner - Journal of the Maritime Industry, September 21, 2009, available at: http://www.professionalmariner.com/DecemberJanuary-2009/Standardized-tractor-tug-commands-for-ship-assist-work/, [accessed 7 May 2014.]

Cole, C. and Trenkner, P., (2012), Whither Maritime English? - 2012, Proc. IMEC 24, Myanmar, October 1-4, 2012, pp. 3-18., available at: http://www.imla.co/sites/ default/files/p2-p7_pimec24proceedings.pdf, [accessed 15 August 2014.].

Communication Breakdown: Standardized Commands Will Improve Tractor Tug Performance \& Minimize Errors, (2009), The Professional Mariner - Journal of the Maritime Industry, October 7, 2009, available at: http://towmasters.wordpress. com/2009/10/07/communication-breakdown-standardized-commands-willimprove-tractor-tug-performance-minimize-errors/, [accessed 8 May 2014.].

Gard News 185, (2007), Is the pilot a part of the bridge team?, February/April 2007, pp. 13-14, available at: http://www.gard.no/ikbViewer/Content/73002/Pilotage, [accessed 21 July 2014.].

Gard News 181, (2006), Pilot on board!, February/April 2006, pp. 16-17, available at: http://www.gard.no/ikbViewer/Content/73002/Pilotage, [accessed 21 July 2014.]. 
Gard News 173, (2004), Who is to blame?, February/April 2004, pp. 22-23, available at: http://www.gard.no/ikbViewer/Content/73002/Pilotage, [accessed 21 July 2014.].

Gauvin, B., (2011), Side bitt or shoulder bitt? Mariners invited to standardize towing terms, The Professional Mariner - Journal of the Maritime Industry, April

2011, available at: http://www.professionalmariner.com/April-2011/Side-bitt-orshoulder-bitt-Mariners-invited-to-standardize-towing-terms/, [accessed 10 May 2014.].

Gauvin, B., (2013), After a 'bitt' of a rhubarb, TSAC accepts the idea of jargon consistency, The Professional Mariner - Journal of the Maritime Industry, June 4 2013, available at: http://www.professionalmariner.com/June-July-2013/After-abitt-of-a-rhubarb-TSAC-accepts-the-idea-of-jargon-consistency/, [accessed 10 May 2014.]

IMO Standard Marine Navigational Vocabulary (SMNV), (1986), London:International Maritime Organisation

IMO Standard Marine Communication Phrases (SMCP), (2001), International Maritime Organisation

Meyer, M., (2012), English as Working Language during Manoeuvring, IFSMA 38th Annual Review 2011-2012, Copenhagen, Denmark, June 14-15, available at: http://
www.ifsma.org/tempannounce/aga38/English\%20as\%20Working\%20Language. pdf, [accessed 25 July 2014.].

Ishikura, A., Sugita, K., Hayashi, Y. and Murai, K., (2013), Proposal for Global Standard Maneuvering Orders for Tugboats, TransNav - the International Journal on Marine NavigationandSafetyofSeaTransportation,7(4),pp.509-513.,availableat:http://www. transnav.eu/Article_Proposal_for_Global_Standard_Ishikura,28,462.html, [accessed 20 May 2014.]., available at: http://www.transnav.eu/files/Proposal\%20for\%20 Global\%20Standard\%20Maneuvering\%20Orders\%20for\%20Tugboats,462.pdf, http://dx.doi.org/10.12716/1001.07.04.05

Strevens, P., (1984), Seaspeak Reference Manual, Pergamon Press.

Trenkner, P., (2013), Are we all on the same page?, Nautilus Telegraph, IMEC International Maritime English Conference - Communication and Culture Matters, pp. 28-29., available at: http://www.imla.co/imec/NautilusFEBR2013.pdf, [accessed 5 August 2014.].

Weeks, F., Glover, A., Johnson, E. and Strevens, P., (1988), Seaspeak Training Manual: Essential English for International Maritime Use, Language Teaching Methodology Series, Pergamon Press. 